\title{
ОТРАЖЕНИЕ УСТАНОВОК ОБЩЕСТВА ЧЕРЕЗ ПРИКЛАДНОЕ ИСКУССТВО
}

\author{
Витаутас Гудонис \\ Шяуляйский университет, Литва
}

\section{Введение}

Работы художников, посвященные человеку с ограниченными возможностями, - это отражение отношения общества к нему. От отношения общества, его установок к взрослым и детям с ограниченными возможностями зависит успех развития их социальной реабилитации и интеграции.

Актуальность исследования заключается в том, что данная тема весьма мало исследована. Качественные социологические методы исследования искусства в своих работах применял узкий круг ученых. Среди таких ученых можно упомянуть профессора по истории искусства Чикагского университета Б.М.Статфорд, которая свои исследования обобщила в 1993 году в монографии «Критицизм тела», профессораофтальмолога глазной клиники Гейдельбергского университета (Германия) В. Яегер $(1976,1979)$ и немецкого тифлолога Дж. Едике (1988). Все эти исследователи в произведениях искусства, в которых были изображены люди с ограниченными возможностями, пытались рассмотреть медицинские и социальные аспекты.

Объект исследования. Репродукции изобразительного искусства, в которых изображается слепой. В исследованиях использована личная коллекция автора, состоящая из более 1000 репродукций. Образцы данных работ собиралась автором в течение 1965 - 2012 г.г. не только в Литве, но и в музеях и национальных галереях Азербайджана, Англии, Армении, Белоруссии, Болгарии, Бразилии, Венгрии, Вьетнама, Голландии, Грузии, Дании, Египта, Индии, Испании, Италии, Китая, Латвии, Малайзии, Норвегии, Португалии, России, Сингапура, Словакии, США, Таджикистана, Туркмении, Турции, Узбекистана, Украины, Филиппин, Финляндии, Франции, Чехии, Швеции, Эстонии, ЮАР, Японии.

Цель исследования. Установить тенденции влияния произведений изобразительного искусства на установки общества к незрячим.

Методы исследования. Историко-генетический, социологический и культурно-исторический анализ литературных источников и произведений искусства.

Гипотезы исследования: большинство реалистических произведений изобразительного искусства объективно отражает жизнь и социальный статус незрячего в обществе; идеализированные произведения изобразительного искусства искаженно отражают жизнь слепого, что 
создает предпосылки для формирования в обществе негативных стереотипов о незрячем человеке и его потенциальных возможностях.

Идеи исследования апробированы автором в трех монографиях, в научных статьях. Часть образцов упомянутой коллекции была представлена в журнале “Mūsų žodis” («Наше слово»), где 1998-2012 г.г. было опубликовано 173 репродукции с их анализом.

Данная тематика исследования в разных аспектах была представлена на конференции Международного совета по образованию лиц с нарушенным зрением (ICEVI) в Сан Пауле (Бразилия, 1997; СанктПетербурге, Россия, 2010), на XXVII международном конгрессе психологов в Стокгольме (Швеция, 2000), на международной конференции «Слепота в разных культурах» в Вильнюсе (2003), на XXVIII международном конгрессе психологов в Пекине (Китай, 2004), на конгрессе психологов Литвы в Каунасе (Литва, 2011), на XXX международном конгрессе психологов в Кейптауне (ЮАР, 2012).

\section{Тематическое распределение и интерпретации образа слепого в изобразительном искусстве}

\section{Образ незрячего музыканта}

Самый древний из известных образцов изображения слепого музыканта в искусстве - фрагмент фрески на могиле визиря Нахта в Луксорах, в Египте, на которой изображен слепой арфист, играющий для пирующих гостей. Этому шедевру искусства более 3000 лет. В 2002 г. наши поиски аналогичных произведений искусства в Египте увенчались успехом. В могильнике фараона Рамзеса II была обнаружена еще не описанная в тифлологической литературе фреска, на которой изображается незрячий музыкант, играющий для фараона. В Египте до сих пор тема незрячего в искусстве является излюбленной. Внешний фасад стены аэропорта Шарм Аль Шейх украшает увеличенная копия фрески “Слепого музыканта" гробницы Нахта. Эти произведения указывают на позитивное отношение к незрячему в Древнем Египте (Рисунок 1).

Довольно много образцов изображения слепого музыканта можно найти в иллюстрациях литературных произведений. Явным лидером такого изображения является повесть «Слепой музыкант», написанная в 1886 году русским писателем В.Короленко. Эта повесть была издана более 50 раз и переведена на 39 языков мира. Книгу иллюстрировала целая плеяда художников. Не все эти иллюстрации можно считать удачными. Напр., в одном из изданий «Слепого музыканта» на английском языке (1967 г.) художник Александр Макнов во всех иллюстрациях, где изображался слепой Петр, использует темный фон, этим подчеркивая слепоту героя и «давящую» его темноту. Такие иллюстрации усиливают у читателей стереотип, будто на слепого всю жизнь мучительно давит 
темнота. Этот стереотип обнаружен и в литературе: «Черные розы и черные лилии и песня жаворонка черна ...» (Бернардас Бразджёнис. Элегия незрячего).

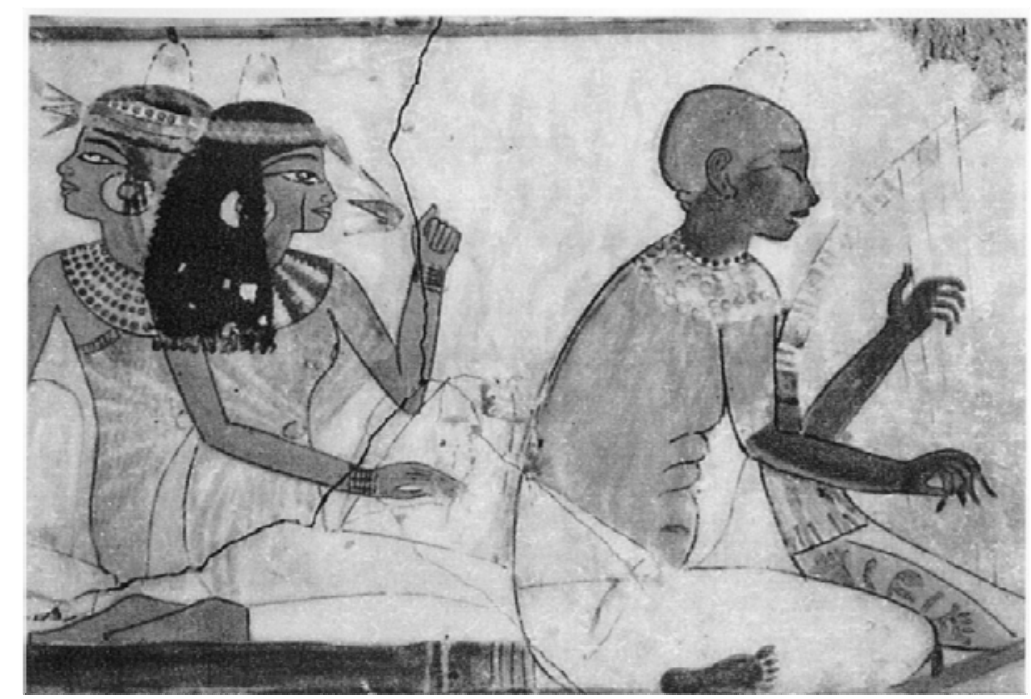

Рисунок 1. Слепой музыкант. Фрагмент фрески гробницы визиря Нахта. Древний Эzunem.

Некоторые художники в названиях своих произведений ошибочно отождествляют слепого музыканта с нищим (напр., Рембрандт и др.). Хотя по своему виду бродячие музыканты часто не отличались от нищих, однако у них совершенно другой социальный статус. Бродячие музыканты не просили подаяния, они на жизнь зарабатывали музыцируя.

\section{Слепье нищие}

Эта тема составляет большую часть нашей коллекции. Обилие темы отражает реальное социальное положение людей с ограниченными возможностями, начиная от искусства Древнего Перу до средних веков и кончая XIX веком. Первые образцы данной темы мы находим в искусстве Древнего Перу. Во времена культуры Моче было до совершенства доведено искусство керамики, в которой, как в летописи, отражалась вся реальная жизнь людей данного периода: от сцен интимной жизни до отражения разных недугов человека.

Современные искусствоведы во многих картинах древности пытаются усмотреть скрытое, т.е. переносное значение. Таким примером может послужить полотно П. Брейгеля «Притча о слепых» (1568), на котором изображены бредущие держащиеся друг за друга незрячие, падающие с обрыва в реку (Рисунок 2).

Современные искусствоведы усматривают в этом отражение государственного кризиса в Нидерландах, другие - духовного падения общества. 


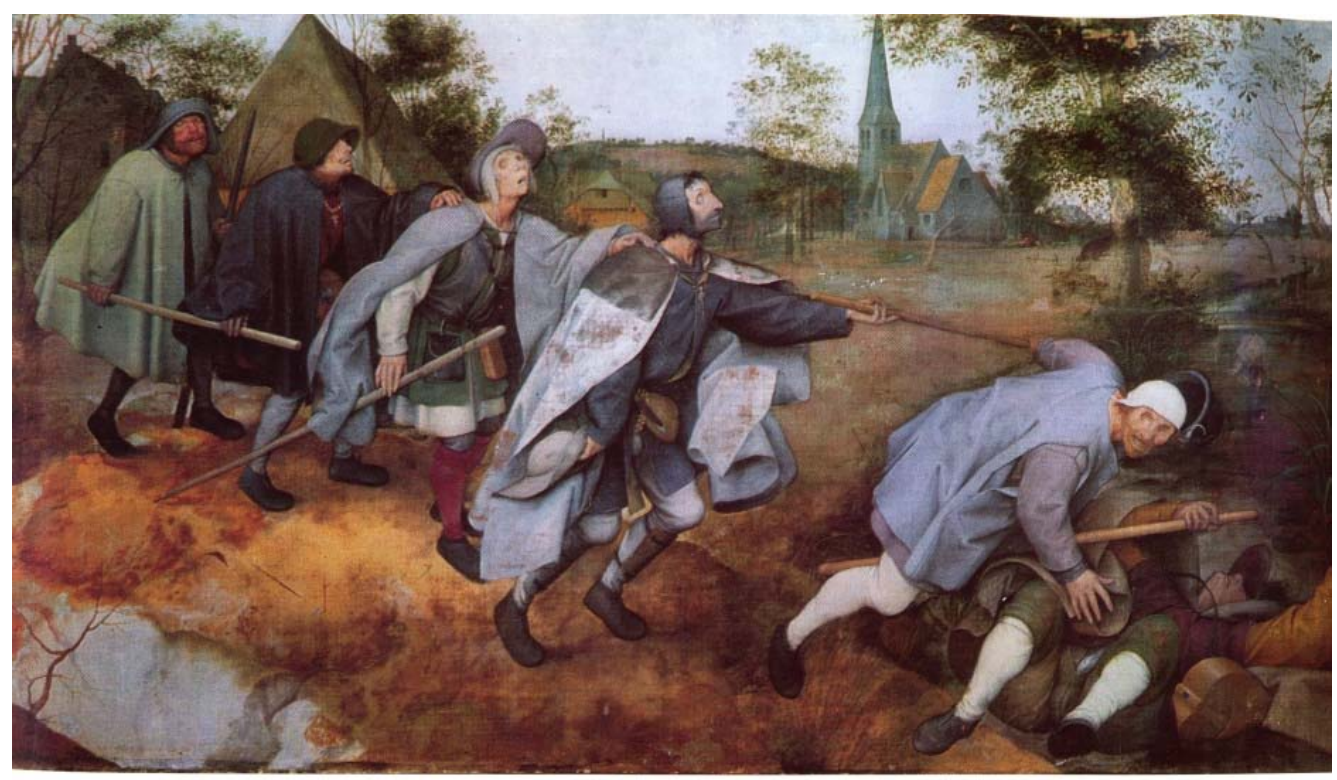

Рисунок 2. П. Брейгель старший. Притча о слепых.

Мы считаем, что это полотно реалистическое и художник писал незрячих с натуры. Таким образом, раскрывая смысл произведения, искусствоведы указали религиозные, общечеловеческие и даже политические версии. Искусствовед Е. Гомбрих заметил, что в любой теории, будь то самая туманная, может скрываться песчинка мудрости, которая подойдет изумруду.

Особую категорию нищих слепые составляли в России (калики перехожие). Они нищенствовали группами, исполняли духовные и народные песни. Картины такого характера, за неимением другой информации о слепых, может сформировать неправильный образ незрячего, как беспомощного человека.

В нашей коллекции много изображений нищих в работах западноевропейских художников. Можно предположить, что такое обилие работ отражало реальное положение. Напр., в 1777 г. нищим был каждый двадцатый житель Франции. Несомненно, большую часть нищих составили люди с ограниченными возможностями, среди которых были и слепые.

\section{Персоналии}

Известных слепых в истории было очень много. Считается, что наиболее известным как среди незрячих, так и среди зрячих является древнегреческий поэт Гомер. Однако существуют и другие мнения. Напр., в 1978 году в впервые изданной книге Майкла Гарта «100 наиболее влиятельных личностей в мировой истории» великий грек среди «сотни» только 98-ой после Гитлера, Сталина и других персоналий.

В античных источниках образ Гомера, исторически реального путешествующего слепого певца, переплетается с фантастическими 
измышлениями, свидетельствующими о том, что подлинных источников о личности Гомера не хватает. В настоящее время неизвестно, как выглядел настоящий поэт. Портрет Гомера сохранился только по античным копиям и является идеализированным, собирательным. О его слепоте было сделано заключение лишь на основе образа «слепого человека из Хиоса» в гимне Аполлону и слепого певца Демодока в «Одиссее». Статуя Гомера вместе с другими, в том числе со статуей Гесиода, стояла в большом храме Микита в Олимпии, воздвигнутом в 460 г. до н. э. Возможно, существуют копии этого раннего портрета Гомера, так как самые архаичные по стилю из его сохранившихся портретов несомненно воспроизводят оригинал того периода. Раньше предполагалось, что это изображение Эпименида, критского жреца и прорицателя, проспавшего в пещере 40 или даже 75 лет. Однако голова принадлежит статуе, которая, к сожалению, нам неизвестна и таким образом, закрытые глаза были истолкованы как признак слепоты. B IV в. до н.э. Гомера больше не изображали слепым или закрытыми глазами (Хафнер, 1981).

Образ Гомера мы находим в древнегреческих скульптурах, древнеримских копиях и в картинах, начиная с древности до наших времен. С портретом Гомера были выпущены монеты и почтовые марки.

Василий Ярошенко (1889-1952) украинский писатель, философ, путешественник, журналист, тифлопедагог и переводчик. Этот незрячий кроме родного украинского языка, знал русский, английский, эсперанто, японский, китайский, хинди, туркменский и языки народностей Севера. По мнению японского литературного критика Хидео Яги, если бы произведения Ярошенко не были бы десятилетия запрещены, то послевоенная японская литература началась бы с более высокой ступени. Это самая высокая оценка творчества В. Ярошенко. Его портрет украшает картинную галерею японского императора.

Но самый известный незрячий после Гомера является гениальный французский изобретатель рельефного письма слепых, тифлопедагог Луи Брайль (1809-1852). Над его портретом работали многие скульпторы и живописцы. В разных странах мира издано множество значков, почтовых марок, открыток, конвертов, медалей, монет с изображением Луи Брайля.

Портреты известных незрячих популяризируют потенциальные возможности слепых и помогают формировать адекватное отношение общества к ним. С целью раскрыть перед обществом потенциальные возможности слепых мы подготовили и издали на литовском и русском языках «Тифлологический словарь имен» (2001), в котором представили биографические данные 1146-ти наиболее известных в мире незрячих из разных стран и исторических периодов. Надеемся, что это поможет формировать адекватное отношение общества к незрячим. 


\section{Незрячие в мифах и легендах}

Исцеление незрячих в иллюстрациях Библии, в церковном искусстве оказало позитивное психотерапевтическое воздействие на устранение нарушений зрения. Чаще всего изображаемые художниками персонажи Библии и других священных книг были Тобит, Павел, Самсон, Исаак. Среди мифологических персонажей наиболее популярными были Эдип, Тересий, Полифем.

\section{Незрячий как символ}

К этой группе относящиеся репродукции по их позитивным и негативным аспектам можно было бы разделить на 3 группы: положительные (любовь, милосердие), отрииательные (зло, гнев, смерть), нейтральные (время, надежда, старость, ночь). Слепота как символ ночи также усиливает стереотип о давящей незрячих темноте.

\section{Незрячие - жертвы войны}

Эту группу произведений искусства составляют репродукции картин, посвященные солдатам, потерявшим зрение в 1812 году, во время I и II мировых и других войнах.

\section{Незрячая женщина}

Эту группу репродукций составляют портреты как конкретных персоналий, так обобщенных, часто идеализированных, незрячих женщин и сюжетные композиции.

\section{Ремесла незрячих}

С древних времен незрячие вили веревки, плели корзины, сети, крутили жернова, были музыкантами и т.п. Произведения, иллюстрирующие ремесла незрячих, предоставляют знания о возможностях профессиональной приспособленности незрячих в разные исторические периоды.

\section{Разная тематика}

Это работы, которые не удалось сгруппировать. Среди них произведения искусства, иллюстрирующие неадекватное отношение общества к слепым. Такие работы можно было бы объединить в серию под названием «незрячий глазами зрячих». Характерным образцом этой серии могло бы быть полотно М. Берингова «Свадьба». Здесь прежде всего проявляется отношение художника к незрячим. На картине художника и молодые, и музыканты, и гости - слепые. Зрителям внушается мысль, что незрячие выбирают себе в жены и мужья только из среды незрячих и что слепые общаются только со слепыми. Такой сегрегационной установкой к людям с ограниченными возможностями обладает и часть людей современного общества. Эти люди, как показывают наши исследования, придерживаются мнения, что дети с ограниченными возможностями должны обучаться. 


\section{Распределение произведений искусства по манере исполнения}

\section{Незрячий, изображаемый идеализированно}

Примером идеализированно изображенного незрячего может послужить картина литовского художника В. Смакаускаса «Нищий», где одетые в белую одежду слепой старик и его проводник - маленький мальчик - идут по дороге. Если бы не название картины, зритель даже не подозревал бы, что это нищие. Аналогичным примером может быть и картина немецкого художника Г. Шпраера «Нищий на улице», где незрячий преувеличенно беззаботно с палочкой в руке и трубкой во рту переходит улицу.

Герой Гражданской войны Николай Островский, автор книги «Как закалялась сталь», в 1935 году при награждении орденом Ленина был парализован и ослепший, что свидетельствует фотография из музея $\mathrm{H}$. Островского г. Сочи. Но в портретах его недуг игнорирован и рисовали его идеализированно, т. е. здоровым, что не отражало действительности.

\section{Незрячий, адекватно изображаемый в реалистическом жанре}

Художников реалистического жанра было достаточно много начиная со средних веков и кончая XX веком. Чаще всего они отражали свое отношение к человеку. Тот же портрет Николая Островского в исполнении китайского художника Гао Манн написан реалистически: писатель изображен в постели, больным, но вместе с тем героическим персонажем.

Появление фотографии дало возможность сравнивать работы изобразительного искусства (как живопись, так и скульптуру) с документальными снимками. Сравнивая представляемые нами работы немецкого художника Г. Цилле «Погреб Бульена» и украинского скульптора Л. Позена «Шарманщик» с фотографиями того же периода (Рисунок 3), можно убедиться в том, что упомянутые художники свои творения создавали с натурщиков, что указывает на объективное отражение действительности.

Таким образом, сравнив фотографии и произведения искусства, можно убедиться не только в схожести натуры, но и определить, с каким чувством относились художники к своим создаваемым образам - с сочувствием, эмпатичностью, состраданием. С другой стороны художник был представителем общества своего времени и через него отражалось отношение всего общества к людям с ограниченными возможностями. 

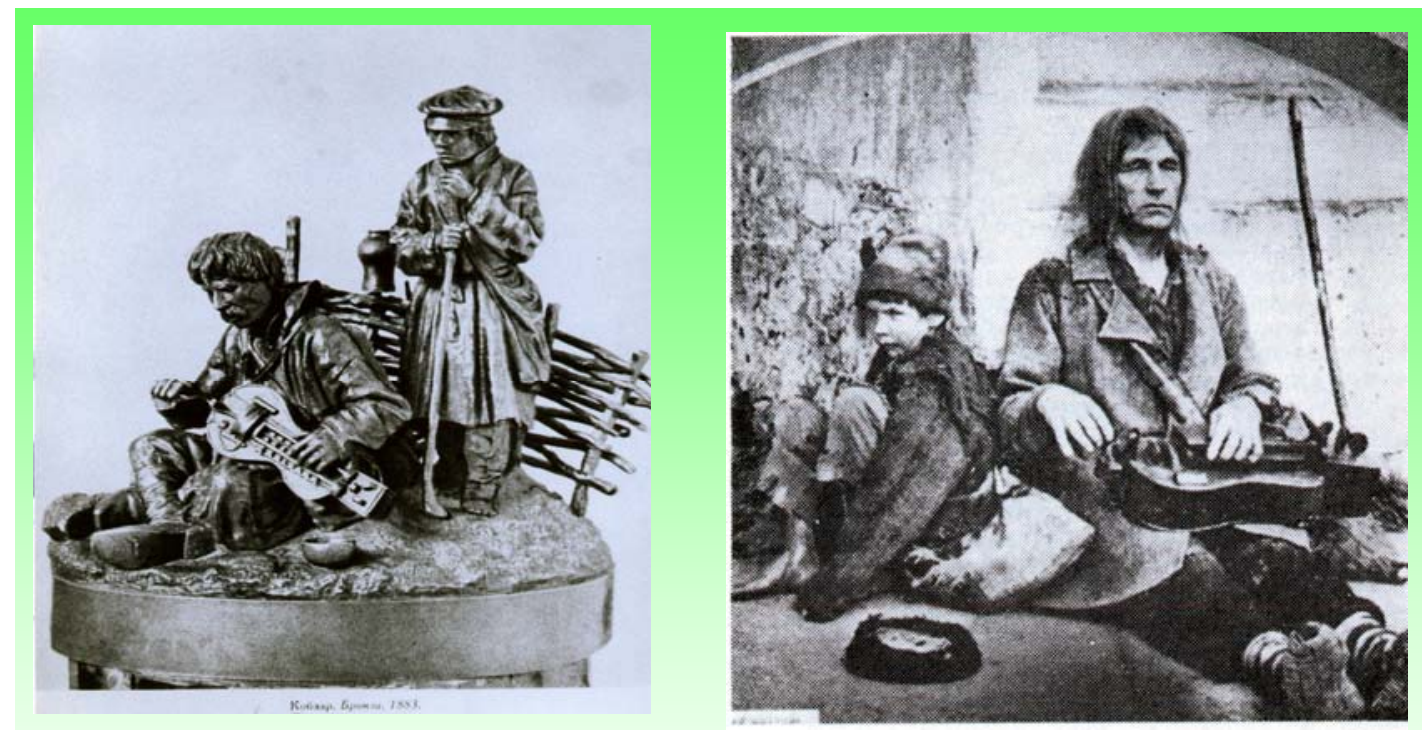

Рисунок 3. Л. Позен. Шарманщик. Фотография. Слепой музыкант. Нач. ХХ в.

\section{Выводы}

- Реалистические произведения изобразительного искусства чаще всего объективно отражают жизнь незрячего человека.

- Образ слепого в искусстве помогает лучше понять отношение общества к незрячему человеку, его занятиям, а также и его общественный статус в разные исторические периоды.

- Произведения искусства, в которых незрячий изображается идеализированно, могут создать условия для формирования в обществе негативных стереотипов о незрячих и их потенциальных возможностях.

- Чаще всего негативные установки общества к незрячим возникают изза дефицита информации о потенциальных возможностях слепых. Для нейтрализации негативного отношения было бы полезно для активной пропаганды потенциальных возможностей незрячих подключить самих слепых интеллектуалов и средства массовой информации. Позитивные установки общества к взрослым людям с ограниченными возможностями создадут более благоприятные условия для их социальной интеграции, а детям со специальными потребностями более благоприятные условия адаптации в общеобразовательных заведениях.

\section{Литература}

1. Gudonis, V. (1985). Lietuvos tiflopedagogikos istorija. Vilnius.

2. Gudonis, V. (1998). P.Breigelis. Alegorija apie akluosius: paveikslo analizè. Mūsu žodis. Nr. 8.

3. Gudonis, V. (2000). Changing of the Attitude towards the Disabled in the Course of History. Ibternational Journal of Psychology. Vol. 35, issue 3/4, June-August. 
4. Gudonis, V., Plepys, S., Žilinskas, J. (2001). Tiflologijos vardų žodynas. Šiauliai: Šiaulių universiteto 1-kla.

5. Gudonis, V. (2006). Aklumas ịvairiose kultūrose. Vilnius.

6. Gudonis, V. (2008). Enciklopedinis tiflologijos žodynas, t. 1. Šiauliai Šiaulių universiteto 1-kla.

7. Gudonis, V. (2009). Enciklopedinis tiflologijos žodynas, t. 2. Šiauliai Šiaulių universiteto 1-kla.

8. Gudonis, V. (2012). The picture of blind musicians in the fine art as a specific reflection of the society's negative attitude. 30th International Congress of Psychology, 22-27 July 2012, Cape Town, South Africa: Abstracts. CapeTown:Taylor and Francis group [IUPsyS Press], p. 703.

9. Jaeger, W. (1976). Heilung des Blinden in der Kunst. München: Jan Thrbecke Verlag Sigmaringen.

10. Korolenko, V. (1987). The Blind Musician. Moscow: Raduga Publishers.

11. Plečkaitis, A. (1977). Pratarmé D.Didro knygai "Laiškas apie akluosius regintiesiems pamokyti". Vilnius.

12. Statford, B.M. (1993). Body criticizm: imaging the unseen in Englightenment art and medicine. Massachusett: Massachusets Institute of Technology.

13. Гомбрих, Е. (1995). История искусства. Вильнюс.

14. Гудонис, В. (1999). Основы и перспективы социальной адаптащии лиц с пониженным зрением. Москва: Академия педагогических и социальных наук.

15. Гудонис, В., Плепис, С., Жилинскас, Й. (2001). Тифлологический словарь имен. Минск.

16. Гудонис, В. (2012). Прикладное искусство как отражение установок общества. Терапия искусством. София: изд-во университета Св.Климента Охридски, с. 347358.

17. Хафнер Г. (1984). Выдающиеся портреты античности: 337 портретов в слове и образе. Москва: Прогресс.

\begin{tabular}{|l|l|}
\hline Витаутас Гудонис & доктор психологических наук, \\
& профессор кафедры Специальной \\
& педагогики Шяуляйского \\
& университета (Литва), \\
& академик Академии педагогических \\
& и социальных наук России. \\
& e-mail: gudonis@su.lt \\
\hline
\end{tabular}

